\title{
Facing natural disasters through the endorsement of authoritarian attitudes
}

\author{
Silvia Russo ${ }^{\mathrm{a}, *}$, Alberto Mirisola $^{\mathrm{b}}$, Francesca Dallago $^{\mathrm{c}}$, Michele Roccato $^{\mathrm{c}}$ \\ ${ }^{a}$ Department of Psychology, University of Torino, Via Verdi 10, 10124, Torino, Italy \\ ${ }^{\mathrm{b}}$ Department of Psychology, Educational Science and Human Movement, University of Palermo, Italy \\ ${ }^{\mathrm{c}}$ Department of Psychology, University of Torino, Italy
}

\section{A R T I C L E I N F O}

Handling Editor: Sander van der Linden

Keywords:

Right-wing authoritarianism

Threat

Natural disasters

\begin{abstract}
A B S T R A C T
We analyzed the relations between exposure to news describing a natural disaster and right-wing authoritarianism (RWA) with 241 Italian adults, surveyed twice, before and after a severe earthquake. Our results were compatible with the idea that the exposure to earthquake news led to an increase in RWA among people who had low, but not among who had relatively high, authoritarian levels before the event. We discuss the findings in terms of compensatory control, and highlight strengths and limitations of the study.
\end{abstract}

\section{Introduction}

Research about the psychological consequences of natural hazards has focused primarily on disaster-related trauma and distress (Osborne \& Sibley, 2013), and on factors that exacerbate or mitigate the development of distress both at the individual (Benight, Swift, Sanger, Smith, \& Zeppelin, 1999; Ruiz \& Hernández, 2014)—and at the community level (Bonaiuto, Alves, De Dominicis, \& Petruccelli, 2016; McGuire et al., 2018). Few studies examined if, in well-established democracies, victims and witnesses of natural disasters change political attitudes (Debbage, Gonsalves, Shepherd, \& Knox, 2014). Consistent with the idea that governments are held accountable for the country's preparedness, response, and recovery (Albrecht, 2017), these studies showed a reduction of political trust and satisfaction with, and support for, the government. In contexts of less established democracies, natural disasters lead to a lowered support for democratic values and practices, indicating discontent with the current political system (Carlin, Love, \& Zechmeister, 2014).

These studies focused on people's tendency to blame politics for the consequences of natural events, but did not address changes in ideological attitudes. To date, whether natural disasters influence opinions, beliefs, and views about the social world remains a largely unexplored issue. In this study, relying on the social-psychological research on authoritarianism, we suggest that low authoritarian people tend to endorse authoritarian attitudes as a way to cope with the exposure to a natural disaster.

\subsection{Authoritarianism and threats}

Right-wing authoritarianism (RWA) is the covariation of authoritarian submission (the willingness to submit to legitimate authorities), conventionalism (the tendency to adhere rigidly to social norms and values), and authoritarian aggression (the aggressiveness toward people deviating from these norms and values) (Altemeyer, 1996). RWA expresses motivational needs for order, social control, and security (Duckitt, 2001) and increases in conditions of societal threat, i.e., of menace stemming from society and posing a danger to the society as a whole (Onraet, Van Hiel, \& Cornelis, 2013), threatening what makes it one and the same (Stenner, 2005). Typical societal threats leading to authoritarianism are economic crises (Sales, 1973), terrorism (Asbrock \& Fritsche, 2013), and criminality (Dallago \& Roccato, 2010).

According to Kay, Gaucher, Napier, Callan, and Laurin (2008), people can try to compensate the loss of perceived control stemming from external threats by supporting sources of external control, such as established authorities and anti-democratic political systems and leaders. Authoritarianism is one of the main social-psychological bases of such support (Jost, Glaser, Kruglanski, \& Sulloway, 2003). Threats undermining social order are fertile ground for the development of authoritarian attitudes (Duckitt \& Fisher, 2003) and their endorsement can be considered as a coping strategy to face such threats (Van Hiel \& De Clercq, 2009). Some studies support the idea that authoritarian responses to threats are useful especially to low authoritarians, who are not already equipped to face the threat-related feelings of uncontrollability (e.g., Mirisola, Roccato, Russo, Spagna, \& Vieno, 2014) and are prone to adopt authoritarian attitudes when exposed to external threats.

\footnotetext{
${ }^{*}$ Corresponding author.

E-mail address: silvia.russo@unito.it (S. Russo).
} 


\subsection{The present study}

We suggest that-similarly to what happens when people are exposed to societal threats-exposure to natural disasters leads to the endorsement of authoritarian attitudes, because it undermines their perception of control and the satisfaction of the need to live in a predictable and secure environment (Afifi, Afifi, \& Merrill, 2014). Not only being a victim of a natural disaster, but also the exposure to information about it can influence negatively people's well-being. For example, exposure to media images about September 11, 2001 and the Iraq war resulted in psychological effects similar to those produced by direct trauma exposure (Silver et al., 2013).

According to Sibley and Bulbulia (2012), exposure to earthquakes makes religion more appealing to people, because religion-just as RWA-serves a palliative function. Moreover, Fritsche, Cohrs, Kessler, and Bauer (2012) showed that reminding participants the negative consequences of climate change fostered their general aggressiveness toward groups perceived as threatening societal safety, i.e., one of the cores of RWA. We reasoned that, if authoritarian responses to threats are actually strategies to cope with the perception of a lack of control stemming from stressful events, we should observe an increment in authoritarianism when people are exposed to news on an uncontrollable and threatening natural event, especially among who, before the earthquake, reported low levels of RWA.

To test this hypothesis, we used data collected before and after a severe earthquake that hit the Abruzzo, an Italian region, on April 6, 2009. The earthquake's main shock, rated 5.9 on the Richter magnitude scale, was felt throughout central Italy. With 308 victims, the earthquake was the deadliest in Italy since 1980. More than 1500 people were injured and about 67,500 people were left homeless; 60,000 buildings were seriously impaired and damages have been estimated to be above 10 billion Euros (Alexander, 2010). As it usually happens after severe natural disasters (e.g., Houston, Pfefferbaum, \& Rosenholtz, 2012), the media gave an extensive coverage of the earthquake, magnifying its dramatic effects (Bobba \& Cepernich, 2009).

We assumed that the Abruzzo earthquake was a stressful event for the whole Italian population and not only for people living in the area. More specifically, based on Ben-Zur, Gil, and Shamshins (2012), we assumed that the Abruzzo earthquake produced a primary traumatization among the people living in Abruzzo, and a secondary traumatization in the people living far from the earthquake epicenter.

\section{Method}

\subsection{Participants and procedure}

In March $2009\left(\mathrm{~T}_{1}\right)$, a web sample of Italian adults filled out a questionnaire about their socio-political opinions, including measures such as nationalism, patriotism, and, importantly for this study, authoritarianism. We recruited the participants by posting announcements for the survey on different social networks, including the websites of two Italian Universities, asking them their willingness to be recontacted for further surveys. In the aftermath of the Abruzzo earthquake (from April 10th till April 13th, $\mathrm{T}_{2}$ ), we contacted again who accepted to be re-contacted, and asked them to fill out a second questionnaire. This allowed us to test the hypothesis on the relations between exposure to natural disaster and RWA above. On both occasions, we informed the participants of their right to refuse to participate in the study or to withdraw consent to participate at any time during the study. The whole procedure was carried out in accordance with the ethical standards of the Italian Association of Psychology.

Four-hundred and forty-seven participants answered the questionnaire at $\mathrm{T}_{1}$ and 241 participants filled out both questionnaires. Participants who completed both questionnaire and those who completed it only at $\mathrm{T}_{1}$ did not differ regarding age, $t(439)=0.00, p=.99$, gender, $\chi^{2}(1)=0.35, p=.56$, and RWA at $\mathrm{T}_{1}, t(435)=-1.36$, $p=.26$. In the following analyses, we included all the participants who responded both at $\mathrm{T}_{1}$ and at $\mathrm{T}_{2}(77.18 \%$ female, mean age $=27.48$, $S D=11.48$ ). Sensitivity power analysis indicated that the sample size required to detect the two-way interaction effect of interest (based on an effect size of $f^{2}=0.07$, as reported in previous research, cf. Russo, Mirisola, \& Roccato, 2014, with a power of .80 and an alpha of .05) was 189 participants.

\subsection{Measures}

At both time points, participants completed a short form of the Italian version of Altemeyer's (1996) RWA scale (Giampaglia \& Roccato, 2002), composed of 14 balanced items, with response options ranging from 1 to $4\left(\alpha=0.88\right.$ both at $T_{1}$ and $\left.T_{2}\right)$, tapping on the covariation of conventionalism, authoritarian submission, and authoritarian aggression. We computed a mean index of RWA, with higher scores indicating higher endorsement of authoritarian attitudes. At $\mathrm{T}_{2}$, we also asked participants to indicate how many hours and minutes they had spent on different media sources (TV programs, radio programs, journal papers, and Internet news) describing the earthquake $(\alpha=0.71)$. We computed a mean index of hours of exposure to earthquake news. Table 1 reports the bivariate correlations and descriptive statistics for these measures.

\section{Results}

We tested our hypothesis via a hierarchic moderated regression predicting RWA at $T_{2}$. In Step 1 , we entered RWA at $T_{1}$ and exposure to earthquake news, using age and gender as control variables, and mean centering the other predictors $\left(R^{2}=0.78, F(4,236)=216.18\right.$, $p<.001)$. In Step 2, we entered the interaction between exposure to earthquake news and RWA at $\mathrm{T}_{1}$. RWA at $\mathrm{T}_{2}$ was predicted by RWA at $\mathrm{T}_{1}(\beta=0.84, b=0.79,95 \%$ CI $[0.73,0.86], t(236)=23.50$, $p<.001$ ), while the effect of exposure to earthquake news did not reach statistical significance $(\beta=0.04, b=0.02,95 \%$ CI $[-0.01,0.05]$, $t(236)=1.45, p=.147)$. Participants' age $(\beta=-0.07, b=0.00$, $95 \%$ CI $[-0.01,0.00], t(236)=-1.98, p=.048)$, but not their gender $(\beta=0.04, \mathrm{~b}=0.05,95 \%$ CI $[-0.03,0.12], t(236)=1.21, p=.226)$, had a significant association with RWA at $\mathrm{T}_{2}$. Entering the interaction between the RWA at $\mathrm{T}_{1}$ and exposure to earthquake news $(\beta=-0.06$, $b=-0.06,95 \%$ CI $[-0.12,-0.01], t(235)=-2.14, p<.05) \mathrm{im}-$ proved significantly the model's fit in the second step $\left(\Delta R^{2}=0.01, F\right.$ $\left.(1,235)=4.57, p<.05, f^{2}=0.02\right)$. Consistent with our expectation, exposure to earthquake news predicted RWA at $\mathrm{T}_{2}$ among participants with low (-1SD) levels of authoritarianism at $\mathrm{T}_{1}$, simple slope $=0.06, t$ $(236)=2.57, p<.05$, but not among those with (relatively) high $(+1$ $S D$ ) levels of authoritarianism at $\mathrm{T}_{1}$, simple slope $=-0.01, t$ (236) $=-0.45, p=.66$. Following Bauer and Curran (2005), we estimated the $95 \%$ CI for RWA at $\mathrm{T}_{1}$ (centered), indicating at what level of RWA at $\mathrm{T}_{1}$ the effect of the exposure to earthquake news on RWA at $\mathrm{T}_{2}$ was significantly positive, non-significant, or significantly negative. The analysis showed confidence bands of RWA at $T_{1}$ between -0.09 and 4.57, within which the relation between exposure to earthquake news

Table 1

Bivariate correlations and descriptive statistics for the study variables.

\begin{tabular}{|c|c|c|c|c|c|c|c|}
\hline & 1. & 2. & 3. & 4. & 5. & $M$ & $S D$ \\
\hline 1. RWA at $T_{1}$ & & $.16^{*}$ & $.88^{* * *}$ & .04 & $-.52^{* * *}$ & 2.06 & 0.54 \\
\hline $\begin{array}{l}\text { 2. Exposure to } \\
\text { earthquake news }\end{array}$ & & & $.19 * *$ & .07 & -.09 & 1.01 & 1.06 \\
\hline 3. RWA at $\mathrm{T}_{2}$ & & & & .08 & $-.51^{* * *}$ & 2.05 & 0.51 \\
\hline 4. Male gender & & & & & $-.15 *$ & .77 & - \\
\hline 5. Age & & & & & & 27.48 & 11.48 \\
\hline
\end{tabular}

Note. RWA $=$ Right-wing authoritarianism. ${ }^{* * *} p<.001,{ }^{* *} p<.01$, ${ }^{*} p<.05$. 


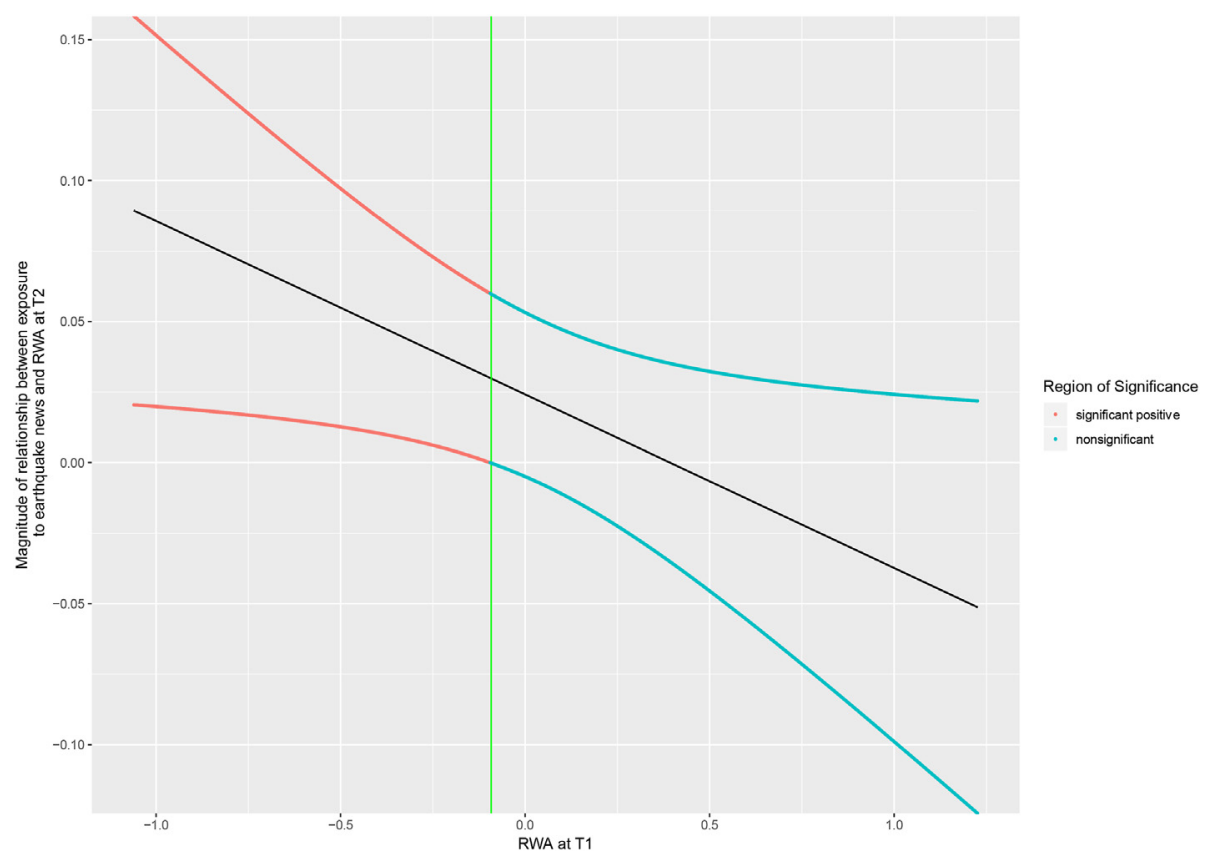

Fig. 1. Moderating effect of RWA (right-wing authoritarianism) at $T_{1}$ on the relation between exposure to information about the earthquake and RWA.

and authoritarianism at $\mathrm{T}_{2}$ was non-significant. In line with our hypothesis, given that RWA at $\mathrm{T}_{1}(M=0, S D=0.54)$ ranged from -1.06 to 1.23 , the effect of the exposure to earthquake news on RWA at $\mathrm{T}_{2}$ was significant and positive only for values of authoritarianism at $\mathrm{T}_{1}$ below -0.09 (see Fig. 1): The lower the authoritarianism at $\mathrm{T}_{1}$, the higher the magnitude of the relationship between exposure to earthquake news and RWA at $\mathrm{T}_{2}$.

As concerns the actual RWA changes, a $2 S D$ standardized change in exposure to earthquake news (from $-1 S D$ to $+1 S D$ ) was accompanied by an increase of 0.5 standardized units of RWA change for low RWA scorers $(-1 S D)$. Among high RWA scorers $(+1 S D)$, a $2 S D$ change in exposure to earthquake news was accompanied by a change in RWA of -0.08 standardized units of RWA, i.e., authoritarianism remained substantially stable. This result did not depend on a trivial regression to the mean (RTM). If a RTM existed, we would have observed an increase in RWA among low RWA scorers and a decrease among high RWA scorers. A mixed-effects model that accounted for regression to the mean led to analogous results. Also, additional analyses, performed using the Tobit model (McBee, 2010) — RWA empirical maximum was the censoring point (cf. Cox \& Oakes, 1984)—helped discard a potential ceiling effect. Indeed, the results remained unchanged. Parallel analyses performed excluding gender and age from the regression equation led to similar results (cf. Tables 1 and 2, in the Supplementary online material).

\section{Discussion}

Psychological research on natural disasters and hazards mainly focuses on their consequences in terms of traumatic stress disorders and distress (Osborne \& Sibley, 2013). However, less is known about the ideological consequences of the exposure to natural disasters. We provided a first evidence about authoritarian shifts as consequences of the exposure to news reporting on a natural disaster, namely a severe earthquake.

We based our study on the idea that authoritarianism could be considered a means to gain compensatory control over one's social environment (Kay et al., 2008) and on the idea that a right-wing belief system can help people manage threats (Jost et al., 2003). Mirisola et al. (2014), showing that societal threat fosters authoritarianism, especially among low authoritarians, concluded that authoritarianism works as a coping mechanism people can use to face the loss of control stemming from living societally threatening situations. This study added to the extant literature suggesting that the above pattern of results holds when a threat stemming from a natural disaster is involved: Even when facing natural threats, non-authoritarians could try to compensate the loss of control by increasing their authoritarianism. This result was the consequence neither of a regression to the mean, nor of a ceiling effect. Also, given the timing of our $\mathrm{T}_{2}$ data collection, we are confident that our findings reflect people's reactions to the earthquake itself, and not to other related issues (Barretta, 2009). Even so, we cannot exclude entirely the possibility that these effects are also partially driven by a societal threat (cf. Supplementary online material).

This does not mean that, immediately after a natural disaster, only high authoritarians can cope with the event. Coping is a multifaceted process, and people can resort to a multitude of strategies, activated as a function of their stable individual characteristics and of contextual features and demands (Snyder \& Pulvers, 2001). Our data showed that, when facing natural disasters, low authoritarians become more similar to high authoritarians, making available a coping strategy that under 'normal conditions' only the former could use.

Our findings are in line with a recent reconceptualization of authoritarianism as an ideological variable including diverse attitudinal expressions, different but related to each other, linked to different strategies to seek security and to different types of threats (Duckitt, Bizumic, Krauss, \& Heled, 2010). Specifically, Duckitt et al. (2010) suggested that authoritarians' motivational goal of maintaining coercive social control stems from 'direct, real, physical threats to societal security, safety, and [people's] well-being' (p. 690). A natural disaster, such as the Abruzzo earthquake, certainly fits within this category of threat.

This study has some limitations to bear in mind. First, we did not measure directly the loss of perceive control following the exposure to news covering the earthquake. Even though we could safely assume that exposure to natural disasters undermines perceptions of control (e.g., Afifi et al., 2014), we could not empirically test its role in explaining the RWA increase among low authoritarians. Second, we did not include questions about people's well-being. This prevented us from understanding whether the observed endorsement of authoritarian attitudes is an effective coping strategy. The question about its efficacy is debated: While some authors found that right-wing attitudes foster 
people's well-being (e.g., Van Hiel \& De Clercq, 2009), others report that RWA can be a risk factor for psychological distress (e.g., Roccato \& Russo, 2017). Lastly, the interactive effect between RWA and exposure to earthquake news might seem weak $\left(f^{2}=0.02\right)$. However, its significance is more substantive than it would appear at a first glance. From the statistical point of view, Aguinis, Beaty, Boik, and Pierce (2005) suggest that a 0.02 effect should be considered at the boundary between medium and large effects. From a practical point of view, small shifts in the public opinion might have relevant political consequences when considering that, in Western democracies, general elections are often won by a thin margin (Callegaro \& Gasperoni, 2008).

We believe that these limitations are counterbalanced by the strengths of the study. First, it was a longitudinal field research, characterized by a significantly higher ecological validity as compared to the standard experimental studies on the threat-RWA links. Second, we used a community sample, much more heterogeneous and representative than the student samples typically used in this field of study. Third, this was the first study to identify the effect of exposure to natural disasters on changes in authoritarianism, which might have both individual and political consequences. In this light, it added to the literature on the origins of authoritarianism. Beyond that of external threat stemming from economy (e.g., Sales, 1973), terrorism (e.g., Asbrock \& Fritsche, 2013), and criminality (e.g., Dallago \& Roccato, 2010), it showed the RWA-enhancing role of external threat stemming from natural disasters. Thus, consistent with Fritsche et al. (2012), our study revealed that the conditional threat-authoritarianism relation can be generalized to other threats that not necessarily jeopardize the 'oneness' and 'sameness' of the society (Stenner, 2005), i.e., to threats emanating from sources entirely unrelated to the target of authoritarian processes. Our study provides a new warning for advocates of the democracy, showing a challenge to the support for democratic systems never highlighted by psychological research. Last, our study added to the literature on the reactions to natural disasters, showing that they can have ideological consequences, especially among non-authoritarians, and even among not directly exposed people.

\section{CRediT authorship contribution statement}

Silvia Russo: Conceptualization, Formal analysis, Writing - original draft. Alberto Mirisola: Conceptualization, Data curation, Formal analysis, Investigation, Methodology, Writing - original draft. Francesca Dallago: Conceptualization, Data curation, Investigation, Methodology. Michele Roccato: Conceptualization, Formal analysis, Methodology, Writing - original draft.

\section{Declaration of competing interest}

None.

\section{Appendix A. Supplementary data}

Supplementary data to this article can be found online at https:// doi.org/10.1016/j.jenvp.2020.101412.

\section{References}

Afifi, W. A., Afifi, T. D., \& Merrill, A. (2014). Uncertainty and control in the context of a category-five tornado. Research in Nursing \& Health, 37, 358-366. https://doi.org/10. 1002/nur.21613.

Aguinis, H., Beaty, J. C., Boik, R. J., \& Pierce, C. A. (2005). Effect size and power in assessing moderating effects of categorical variables using multiple regression: A 30 year review. Journal of Applied Psychology, 90, 94-107. https://doi.org/10.1037/ 0021-9010.90.1.94.

Albrecht, F. (2017). Government accountability and natural disasters: The impact of natural hazard events on political trust and satisfaction with governments in Europe. Risk, Hazards \& Crisis in Public Policy, 8, 381-410. https://doi.org/10.1002/rhc3. 12122.

Alexander, D. E. (2010). The L'Aquila earthquake of 6 April 2009 and Italian government policy on disaster response. Journal of Natural Resources Policy Research, 2, 325-342. https://doi.org/10.1080/19390459.2010.511450.

Altemeyer, B. (1996). The authoritarian specter. Cambridge, MA: Harvard University Press.

Asbrock, F., \& Fritsche, I. (2013). Authoritarian reactions to terrorist threat: Who is being threatened, the Me or the We? International Journal of Psychology, 48, 35-49. https:// doi.org/10.1080/00207594.2012.695075.

Barretta, P. (2009). La rappresentazione del sisma nei telegiornali e il ruolo dei minori [The representation of the earthquake in the daily press and the role of the minors]. Retrieved May 14, 2018, from Osservatorio di Pavia Web site:.

Bauer, d. J., \& Curran, P. J. (2005). Probing interactions in fixed and multilevel regression: Inferential and graphical techniques. Multivariate Behavioral Research, 40, 373-400. https://doi.org/10.1207/s15327906mbr4003 5.

Ben-Zur, H., Gil, S., \& Shamshins, Y. (2012). The relationship between exposure to terror through the media, coping strategies and resources, and distress and secondary traumatization. International Journal of Stress Management, 19, 132-150. https://doi. org/10.1037/a0027864.

Benight, C. C., Swift, E., Sanger, J., Smith, A., \& Zeppelin, D. (1999). Coping self-efficacy as a mediator of distress following a natural disaster. Journal of Applied Social Psychology, 29, 2443-2464. https://doi.org/10.1111/j.1559-1816.1999.tb00120.x.

Bobba, G., \& Cepernich, C. (2009). La costruzione dell'eccezionale' come risorsa per il consenso: Il terremoto tra celebrazione mediale e opportunismo politico [Building the 'exceptional' as a resource for gaining consensus: The earthquake between media celebration and political opportunism]. Meridiana, 65/66, 153-184.

Bonaiuto, M., Alves, S., De Dominicis, S., \& Petruccelli, I. (2016). Place attachment and natural hazard risk: Research review and agenda. Journal of Environmental Psychology, 48, 33-53. https://doi.org/10.1016/j.jenvp.2016.07.007.

Callegaro, M., \& Gasperoni, G. (2008). Accuracy of pre-election polls for the 2006 Italian parliamentary elections: Too close to call. International Journal of Public Opinion Research, 20, 148-170. https://doi.org/10.1093/ijpor/edn015.

Carlin, R. E., Love, G. J., \& Zechmeister, E. J. (2014). Natural disaster and democratic legitimacy: The public opinion consequences of Chile's 2010 earthquake and tsunami. Political Research Quarterly, 67, 3-15. https://doi.org/10.1177/1065912913495592.

Cox, D. R., \& Oakes, D. (1984). Analysis of survival data. London, UK: Chapman \& Hall. Dallago, F., \& Roccato, M. (2010). Right-wing authoritarianism, big five, and perceived threat to safety. European Journal of Personality, 24, 106-122 doi:101002/per.745.

Debbage, N., Gonsalves, N., Shepherd, J. M., \& Knox, J. A. (2014). Superstorm sandy and voter vulnerability in the 2012 US presidential election: A case study of New Jersey and Connecticut. Environmental Hazards, 13, 181-199. https://doi.org/10.1080/ 17477891.2014.891500.

Duckitt, J. (2001). A dual-process cognitive-motivational theory of ideology and prejudice. In M. P. Zanna (Vol. Ed.), Advances in experimental social psychology: Vol. 33, (pp. 41-113). San Diego, CA: Academic Press.

Duckitt, J., Bizumic, B., Krauss, S. W., \& Heled, E. (2010). A tripartite approach to rightwing authoritarianism: The Authoritarianism-Conservatism-Traditionalism model. Political Psychology, 31, 685-715. https://doi.org/10.1111/j.1467-9221.2010. 00781.x.

Duckitt, J., \& Fisher, K. (2003). The impact of social threat on worldview and ideological attitudes. Political Psychology, 24, 199-222. https://doi.org/10.1111/0162-895X. 00322.

Fritsche, I., Cohrs, J. C., Kessler, T., \& Bauer, J. (2012). Global warming is breeding social conflict: The subtle impact of climate change threat on authoritarian tendencies. Journal of Environmental Psychology, 32, 1-10. https://doi.org/10.1016/j.jenvp.2011. 10.002.

Giampaglia, G., \& Roccato, M. (2002). La scala di autoritarismo di destra di Altemeyer: Un'analisi con il modello di Rasch per la costruzione di una versione italiana [Altemeyer's right-wing authoritarianism scale: An Italian validation performed using the Rasch model]. TPM - Testing, Psychometrics, Methodology in Applied Psychology, 9(2), 93-111.

Houston, J. B., Pfefferbaum, B., \& Rosenholtz, C. E. (2012). Disaster news: Framing and frame changing in coverage of major U.S. natural disasters, 2000-2010. Journalism \& Mass Communication Quarterly, 89, 606-623. https://doi.org/10.1177/ 1077699012456022

Jost, J. T., Glaser, J., Kruglanski, A. W., \& Sulloway, F. J. (2003). Conservatism as motivated social cognition. Psychological Bulletin, 129, 339-375. https://doi.org/10. 1037/0033-2909.129.3.339.

Kay, A., Gaucher, D., Napier, J. L., Callan, M. J., \& Laurin, K. (2008). God and the government: Testing a compensatory control mechanism for the support of external systems. Journal of Personality and Social Psychology, 95, 18-35. https://doi.org/10. 1037/0022-3514.95.1.18.

McBee, M. (2010). Modeling outcomes with floor or ceiling effects: An introduction to the Tobit model. Gifted Child Quarterly, 54, 314-320. https://doi.org/10.1177/ 0016986210379095.

McGuire, A. P., Gauthier, J. M., Anderson, L. M., Hollingsworth, D. W., Tracy, M., Galea, S., et al. (2018). Social support moderates effects of natural disaster exposure on depression and posttraumatic stress disorder symptoms: Effects for displaced and nondisplaced residents. Journal of Traumatic Stress, 31, 223-233. https://doi.org/10. $1002 /$ jts. 22270 .

Mirisola, A., Roccato, M., Russo, S., Spagna, G., \& Vieno, A. (2014). Societal threat to safety, compensatory control, and right-wing authoritarianism. Political Psychology, 35, 795-812. https://doi.org/10.1111/pops.12048.

Onraet, E., Van Hiel, A., \& Cornelis, I. (2013). Threat and right-wing attitudes: A crossnational approach. Political Psychology, 34, 791-803. https://doi.org/10.1111/pops. 12014.

Osborne, D., \& Sibley, C. G. (2013). After the disaster: Using the big-five to predict changes in mental health among survivors of the 2011 christchurch earthquake. Disaster Prevention and Management, 22, 456-466. https://doi.org/10.1108/DPM-09- 
2013-0161.

Roccato, M., \& Russo, S. (2017). Right-wing authoritarianism, societal threat to safety, and psychological distress. European Journal of Social Psychology, 47, 600-610. https://doi.org/10.1002/ejsp.2236.

Ruiz, C., \& Hernández, B. (2014). Emotions and coping strategies during an episode of volcanic activity and their relations to place attachment. Journal of Environmental Psychology, 38, 279-287. https://doi.org/10.1016/j.jenvp.2014.03.008.

Russo, S., Mirisola, A., \& Roccato, M. (2014). Symbolic threat fosters right-wing authoritarianism only among low authoritarians. TPM - Testing, Psychometrics,

Methodology in Applied Psychology, 21, 197-211. https://doi.org/10.4473/tpm21.2.6.

Sales, S. M. (1973). Threat as a factor in authoritarianism: An analysis of archival data. Journal of Personality and Social Psychology, 28, 44-57. https://doi.org/10.1037/ h0035588.

Sibley, C. G., \& Bulbulia, J. (2012). Faith after an earthquake: A longitudinal study of religion and perceived health before and after the 2001 cristchurch New Zealand earthquake. PloS One, 7, e49648. https://doi.org/10.1371/journal.pone-0049648.

Silver, R. C., Holman, E. A., Andersen, J. P., Poulin, M., McIntosh, D. N., \& Gil-Rivas, V. (2013). Mental-and physical-health effects of acute exposure to media images of the September 11, 2001, attacks and the Iraq War. Psychological Science, 24, 1623-1634. https://doi.org/10.1177/0956797612460406.

Snyder, C. R \& Pulvers, K. M. (2001). Dr. Seuss, the coping machine, and "On the place you go". In C. R. Snyder (Ed.). Coping with stress: Effective people and processes (pp. 329). Oxford: Oxford University Press.

Stenner, K. (2005). The authoritarian dynamic. New York, NY: Cambridge University Press. Van Hiel, A., \& De Clercq, B. (2009). Authoritarianism is good for you: Right-wing authoritarianism as a buffering factor for mental distress. European Journal of Personality, 23, 33-50. https://doi.org/10.1002/per.702. 